\title{
AVALIAÇÃO DE ESTRUTURA DE BAMBU COMO ELEMENTO CONSTRUTIVO PARA CASA DE VEGETAÇÃ̃ ${ }^{1}$
}

\author{
WELLINGTON MARY ${ }^{2}$, CLAUDIO S. KENMOCHI ${ }^{3}$, NILTON N. COMETTI ${ }^{4}$, \\ PAULO M. LEAL ${ }^{5}$
}

\begin{abstract}
RESUMO: O uso da tecnologia do cultivo protegido no Brasil, para a produção de hortaliças e plantas ornamentais, passou por diversas fases de adaptação, visando a atender às necessidades de oferta e de qualidade dos produtos, com a preocupação de minimizar os custos de produção e os efeitos negativos do clima. A grande maioria dessas adaptações partiu da iniciativa dos próprios agricultores, utilizando-se de diferentes materiais e de outros artifícios para contornar problemas cotidianos. O experimento foi realizado na área da Faculdade de Engenharia Agrícola/UNICAMP, no período compreendido entre dezembro de 2002 e janeiro de 2003, com o objetivo de avaliar as deformações do sistema construtivo de estrutura de bambu para utilização em casa de vegetação, em diferentes espaçamentos entre colunas e sob diferentes esforços verticais de cargas. Testou-se o uso de vigas e colunas construídas com colmos de bambu da espécie Bambusa tuldoides Munro e estruturadas com espaçadores de plástico, especialmente projetados para facilitar e padronizar a construção, conferindo-lhe maior resistência e estabilidade. Foram avaliados três espaçamentos entre colunas $(2,0 ; 2,5$ e 3,0 m) sob diferentes esforços de carga, dos quais o melhor resultado foi obtido com o espaçamento de $2,5 \mathrm{~m}$.
\end{abstract}

PALAVRAS-CHAVE: material alternativo, estufa, cultivo protegido.

\section{EVALUATION OF THE BAMBOO STRUCTURE USE AS CONSTRUCTIVE ELEMENT FOR GREENHOUSES}

\begin{abstract}
The use of technology to protect and produce vegetables and ornamental plants was developed over several adaptation phases that supported the demand for quality and amount of products. These developments also reduced production costs and climate damage to the crops. Many of these adaptations were carried out by farmers on their own initiative, using different materials and devices to solve their problems. This study was carried out at Agricultural Engineering College - Campinas University/UNICAMP, from December 2002 to January 2003, with the objective of evaluating the deformations of the constructive system of bamboo structure for greenhouses, submitted to different spacing among columns, and different vertical strains. It was tested the use of beams and columns built with bamboo stems from the specie Bambusa tuldoides Munro. The beams and columns were tied together with plastic spacing parts, specially designed to facilitate and standardize the construction of the building, providing more resistance and stability. Three column spaces $(2.0,2.5$ and $3.0 \mathrm{~m})$ were evaluated under different load strains. The best result was obtained with a spacing of $2.5 \mathrm{~m}$.
\end{abstract}

KEYWORDS: alternative material, greenhouse, protect crops.

\footnotetext{
${ }^{1}$ Extraído da tese de doutorado do primeiro autor.

2 Prof. Dr. Departamento de Arquitetura e Urbanismo, Universidade Federal Rural do Rio de Janeiro, UFRuralRJ, Seropédica - RJ, wmary@ufrrj.br

${ }^{3}$ Curso de Engenharia Agrícola, FEAGRI, Universidade Estadual de Campinas, Campinas - SP. Bolsista CNPq/PIBIC

${ }^{4}$ Prof. Dr., Escola Agrotécnica Federal de Colatina, Colatina - ES.

${ }^{5}$ Prof. Dr., Departamento de Construções Rurais e Ambiência, FEAGRI, Universidade Estadual de Campinas, Campinas - SP. Recebido pelo Conselho Editorial em: 9-12-2005

Aprovado pelo Conselho editorial em: 21-2-2007
} 


\section{INTRODUÇÃO}

No Brasil, houve rápido crescimento do cultivo protegido de hortaliças no início da década de 90. As estimativas apontavam uma área de cultivo protegido com cerca de 2.000 ha, com taxa anual de crescimento de $30 \%$, alcançando-se a cifra de 20.000 ha na virada do milênio (DELLA VECCHIA \& KOCH, 1999). Esse crescimento foi desordenado e sem tecnologia adequada, o que propiciou o surgimento de vários casos de insucessos, incluindo a construção de modelos de estruturas inadequados às condições climáticas peculiares de cada local, culminando por levar muitos produtores a abandonar a atividade após algum tempo (FONTES, 2000). Outro fator que deve ser levado em consideração é a condição socioeconômica dos produtores, principalmente o pequeno produtor, que não estava adaptado à tecnologia e não possuía condições financeiras para iniciar na atividade, necessitando, então, de materiais alternativos de baixo custo e de fácil aplicação.

Diversos modelos de estruturas de proteção e de elementos construtivos têm sido comercializados. Entretanto, o pequeno produtor necessita de tecnologia diferenciada para a utilização de materiais alternativos, que estejam disponíveis na propriedade, como, por exemplo, o bambu, a fim de reduzir os custos de instalação. O bambu, por ser um material muito versátil, largamente utilizado nos países asiáticos e latinos como material de construção e encontrado comumente nas propriedades agrícolas, torna-se uma opção interessante como matéria-prima para o estudo e desenvolvimento de casas de vegetação. Possui ainda excelentes características mecânicas e pode ser destacado seu rápido crescimento e rusticidade (HIDALGO LÓPEZ, 1974; GHAVAMI, 1992).

O presente trabalho teve o objetivo de avaliar a utilização de colmos de bambu da espécie Bambusa tuldoides Munro, como elemento construtivo da casa de vegetação, em diferentes espaçamentos entre colunas e sob diferentes esforços de cargas, a fim de se determinar o maior espaçamento possível, visando à diminuição de custos de material e de mão-de-obra, sem o comprometimento de deformação da estrutura que afetasse as características do plástico de cobertura, ou seja, tensionamento distribuído homogeneamente, não promovendo a formação de rugas ou dobras que favoreçam o acúmulo de água de chuva.

Apesar de a existência de outras espécies de bambu oferecerem maior resistência em função do diâmetro de colmo e de parede, optou-se pelo Bambusa tuldoides Munro (taquara), por ser mais facilmente encontrado nas propriedades dos agricultores, ao qual se resume o presente trabalho, a fim de melhorar a sua resistência por meio da construção de colunas e vigas em virtude de seu menor diâmetro.

\section{MATERIAL E MÉTODOS}

Foram realizados três ensaios de esforços de carga entre dezembro de 2002 e janeiro de 2003, a fim de se determinar o melhor espaçamento entre pórticos (seções) para a instalação de uma casa de vegetação, construídos com vigas e colunas feitas de colmos de bambu da espécie B. tuldoides. Foram utilizados três tipos de espaçamentos entre os pórticos: 2,0; 2,5 e 3,0 m. Os colmos de bambu para a construção das vigas e das colunas foram coletados no mês de novembro de 2002, na área do Instituto Agronômico de Campinas (IAC), e imersos em um lago por um período de 10 dias para eliminar amido, açúcares e insetos, conforme recomendação descrita por RAJ (1991). Os colmos, com diâmetro de $4 \mathrm{~cm}$ em média, foram colocados em túnel baixo para antecipar sua secagem, necessária para evitar a variação de seu diâmetro após a construção das vigas e colunas (HIDALGO LÓPEZ, 1974; BERALDO, 2002).

Foram utilizados três colmos de bambu apoiados em espaçadores de plástico (polipropileno), especialmente desenhados e produzidos para tal finalidade, distanciados em $60 \mathrm{~cm}$ ao longo da viga. $\mathrm{Na}$ amarração, foram utilizados dois fios de arame galvanizado número 12 , colocados um de cada lado do espaçador (Figuras 1 e 2), e tensionados com uma torquês. 


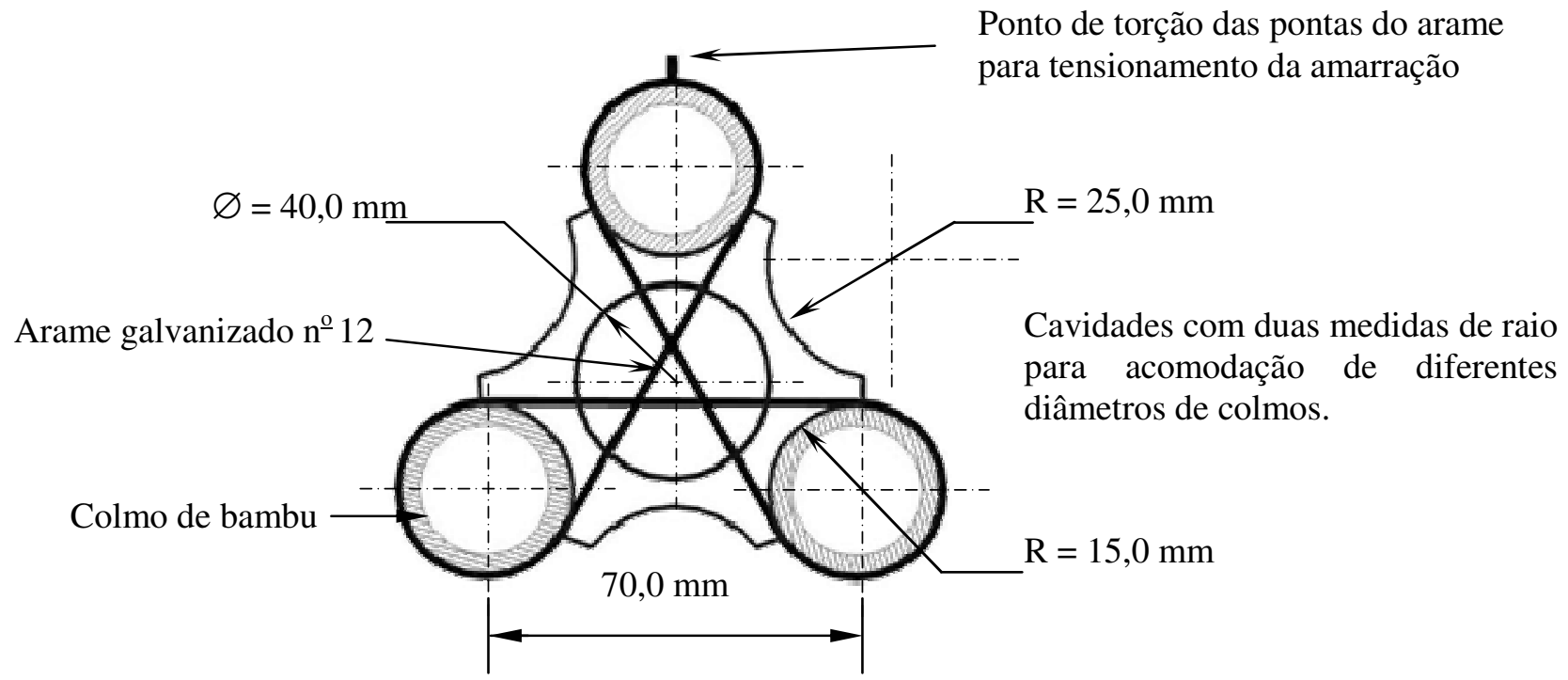

FIGURA 1. Método de amarração dos colmos no espaçador para construção de vigas e colunas.

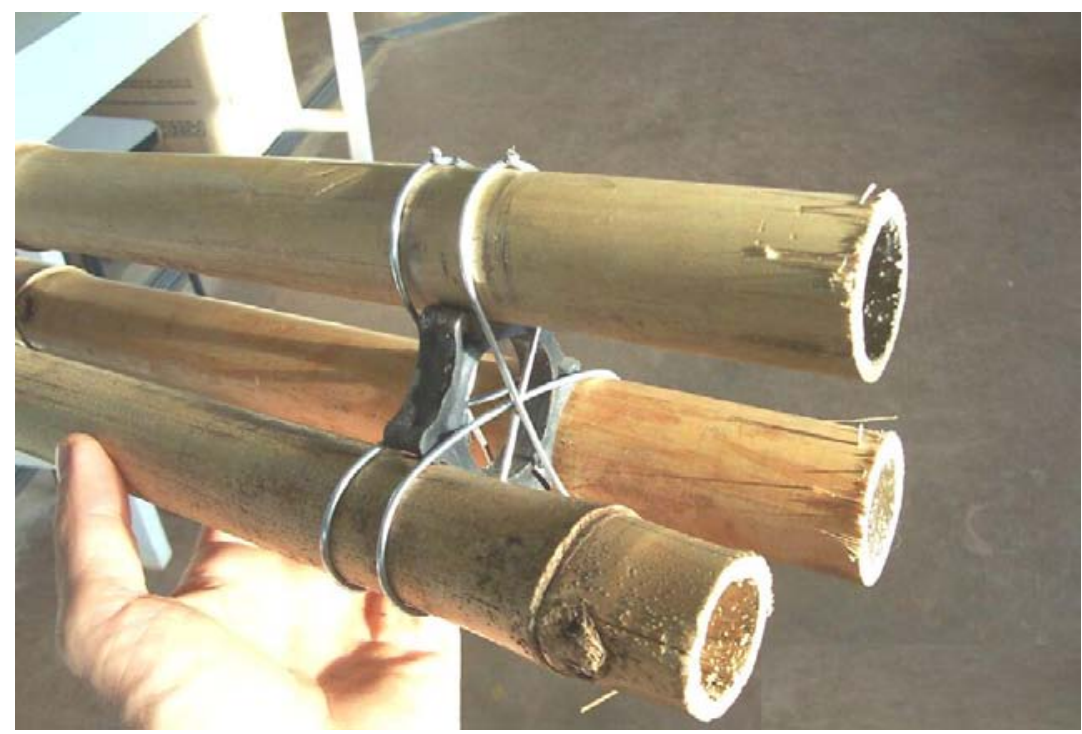

FIGURA 2. Detalhe da amarração.

\section{Ensaios de cargas}

Foram aplicados carregamentos aos pórticos formados com 6,0 $\mathrm{m}$ x 4,0 $\mathrm{m}$ (largura $\mathrm{x}$ altura), sendo os efeitos das cargas sobre os pórticos (transversal e longitudinal) analisados em diferentes espaçamentos entre cada pórtico transversal: 2,0; 2,5 e 3,0 m.

Foram registradas as variações de deformação em pontos predeterminados $(1 ; 2 ; 3 ; 5$ e 6$)$ para o pórtico longitudinal e nos pontos 1; 2 e 4 para o pórtico transversal (Figuras 3 e 4).

Foi estabelecido o limite de $100 \mathrm{~mm}$ como o deslocamento vertical máximo admissível (ponto crítico) para se encerrarem os testes em quaisquer dos pontos estudados, uma vez que uma variação maior do que essa poderia comprometer o alinhamento e a estabilidade da estrutura e do filme de cobertura. Para a realização dos ensaios, foram utilizadas balizas (miras e tripés) de uso topográfico para medir os deslocamentos verticais das vigas e colunas após a aplicação das cargas. O nível de precisão esteve em torno de 5,0 $\mathrm{mm}$ em função do deslocamento do eixo horizontal das colunas e vigas. 

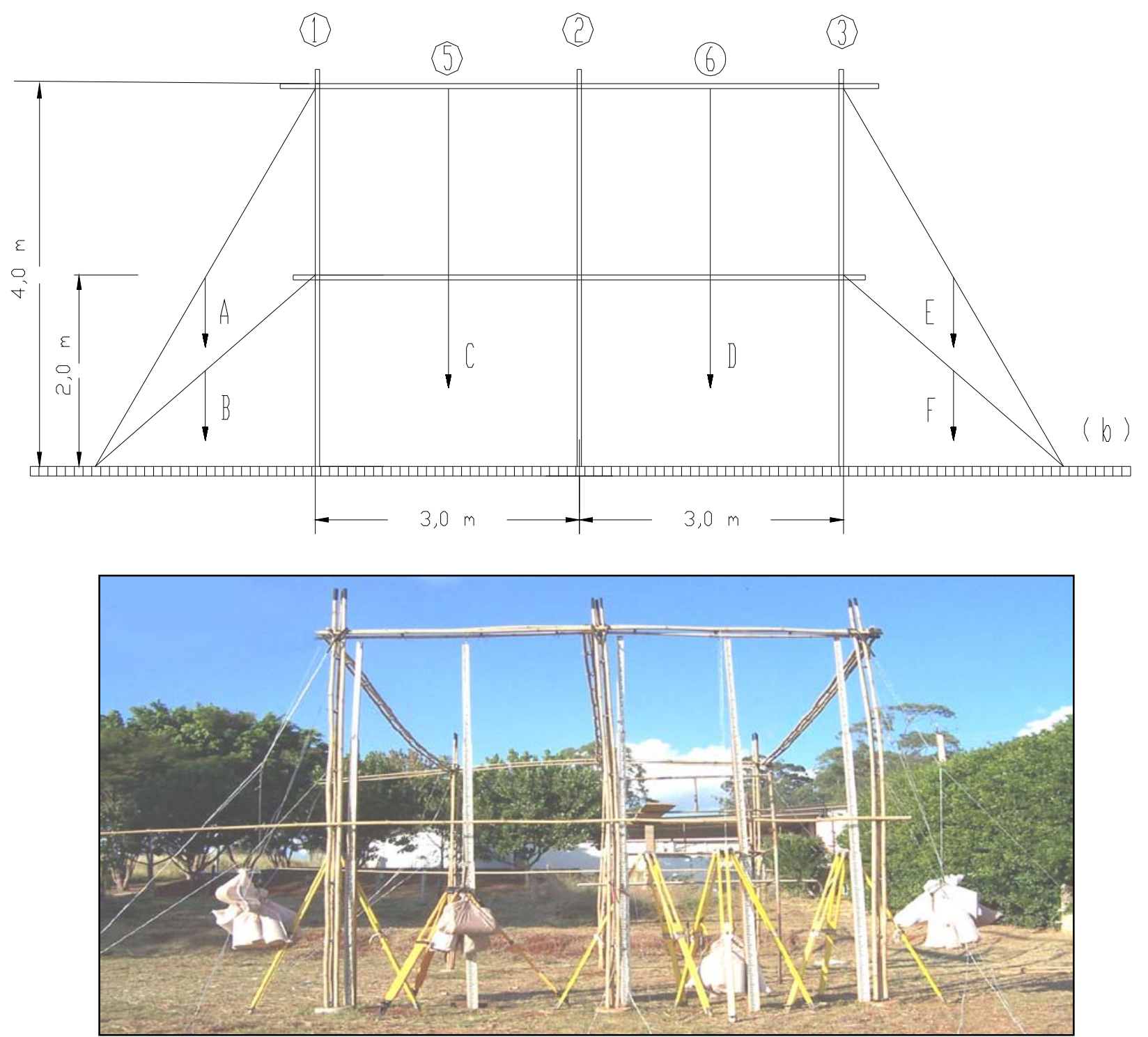

FIGURA 3. Croquis e foto do ensaio de campo da distribuição das cargas aplicadas e os pontos de medição dos deslocamentos no pórtico longitudinal.

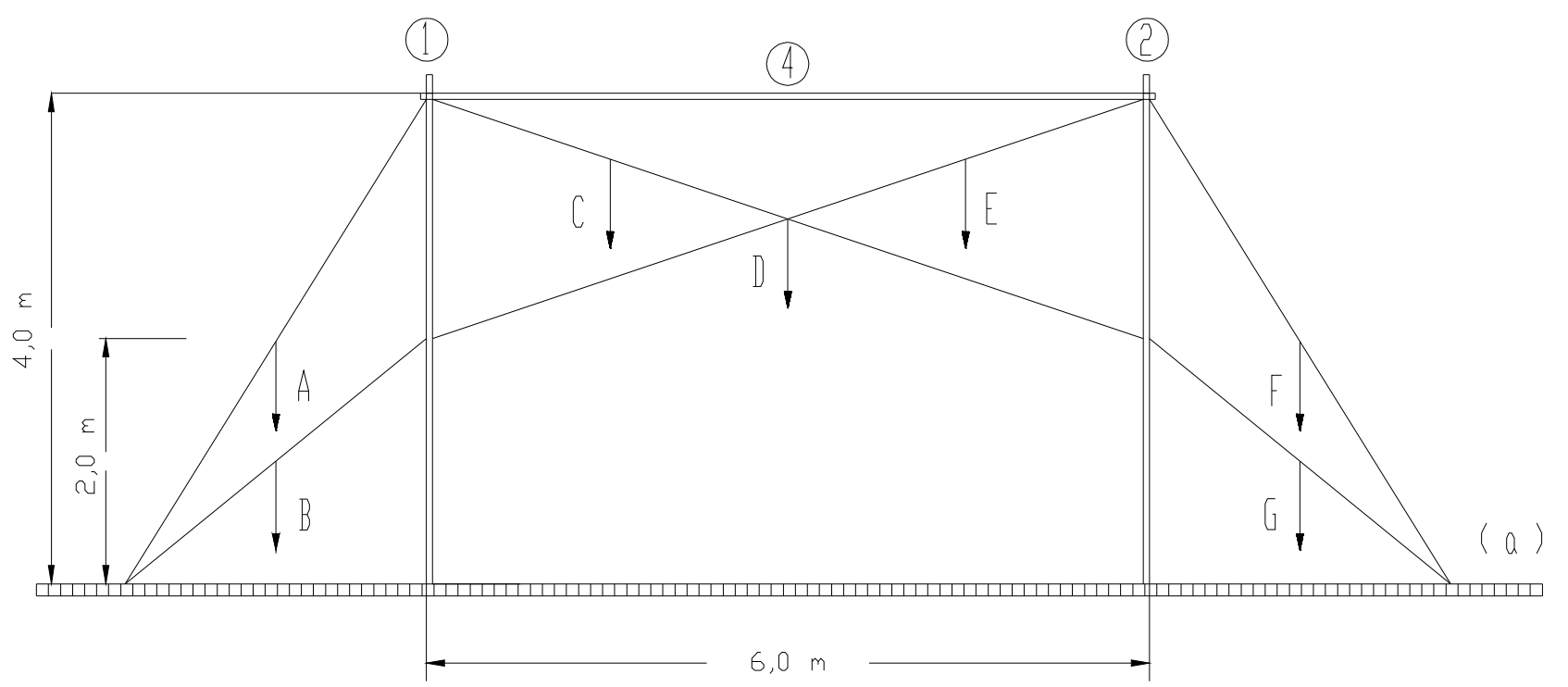

FIGURA 4. Croquis do ensaio de campo da distribuição das cargas aplicadas e os pontos de medição dos deslocamentos verticais no pórtico transversal. 
Utilizou-se arame galvanizado $(\varnothing=2,0 \mathrm{~mm}$ ) na amarração entre as vigas e as colunas. Outro arame de aço ovalado (utilizado para cercas de gado) foi utilizado como simulação de uma carga pontual exercida pelo filme plástico, que serviu para fixar as cargas C, D e E (Figura 4).

Os detalhes de fixação entre as vigas e colunas, bem como o engaste das colunas na sapata, estão demonstrados nas Figuras 5 e 6.

Corte transversal Vista superiror

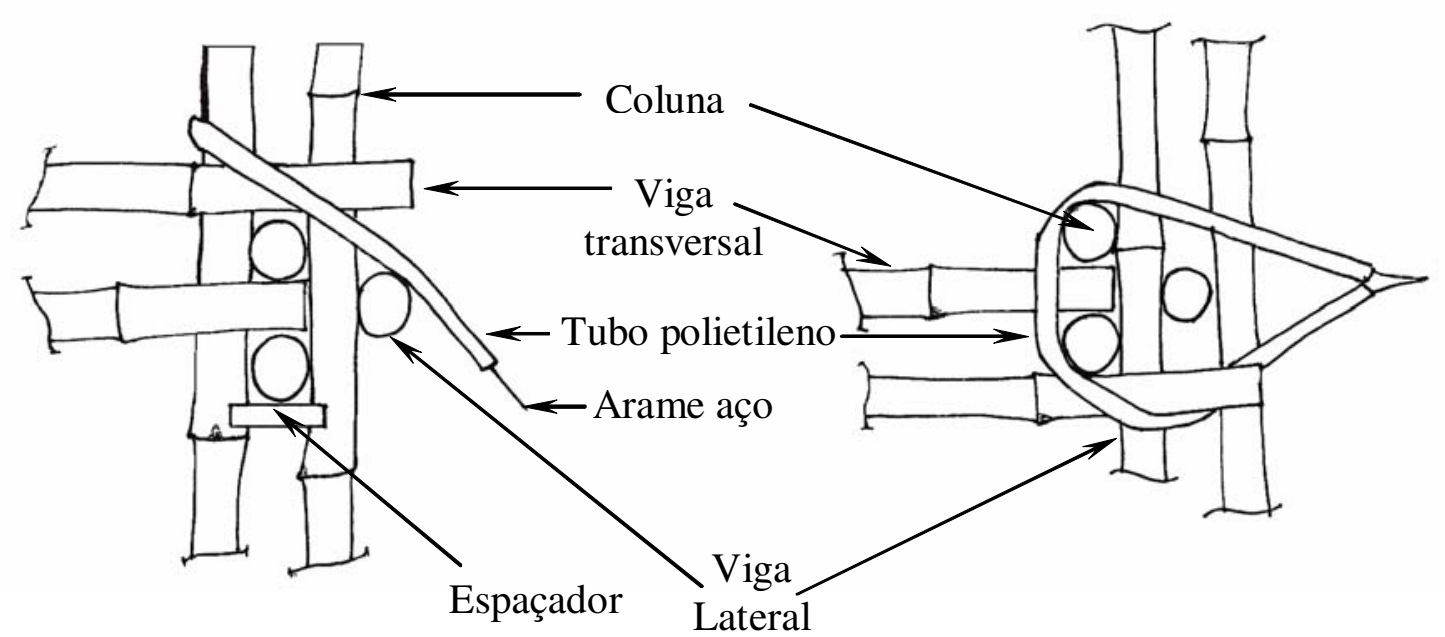

FIGURA 5. Detalhe da amarração.

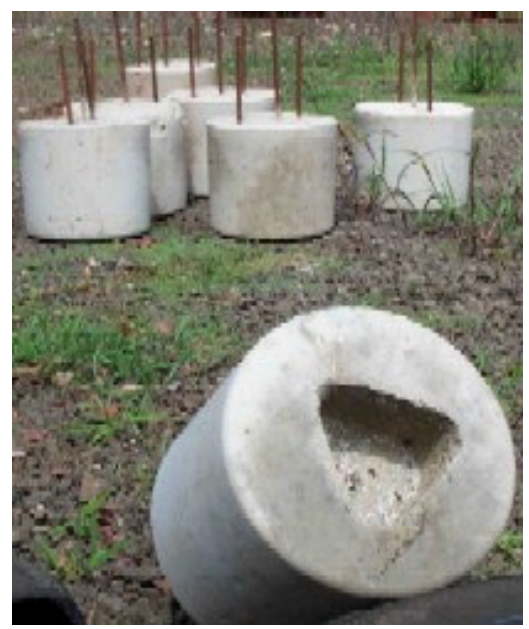

FIGURA 6. Base de concreto para fixação (encaixe) das colunas.

Cargas de $28 \mathrm{kgf}$ e $36 \mathrm{kgf}$ (sacos contendo corpos de prova) foram distribuídas e fixadas nos tirantes representados pelos pontos (A, B, C, D, E, F e G) em cada pórtico (Figuras 3 e 4), aplicando-se gradativamente as cargas, totalizando 184; 284 e $348 \mathrm{kgf}$ em cada simulação no pórtico transversal, e 184; 384 e 496 kgf, no pórtico longitudinal.

Nas Tabelas 1 e 2, estão apresentadas as variações de carga com as distribuições de pesos em cada ponto avaliado.

Os deslocamentos foram medidos nas colunas e na mediana das vigas entre colunas, pontos 1; $2 ; 3$ e 4; 5; 6, respectivamente (Figuras 3 e 4). Foram realizadas três repetições do ensaio no pórtico transversal. No pórtico longitudinal, foram realizadas seis repetições nos pontos 1 ; 2 e 3 , e quatro repetições nos pontos 5 e 6 . 
Foi utilizado o esquema fatorial $3 \times 3$ (três pontos e três cargas) para a avaliação dos deslocamentos verticais das colunas. Para o caso do pórtico transversal, foi considerado o ponto 4 como ponto crítico do efeito dos esforços. Para o deslocamento das vigas no pórtico longitudinal, foram considerados os pontos 5 e 6 como pontos críticos, pois, entre as colunas, a deformação da viga pode afetar a superfície do filme plástico de cobertura.

TABELA 1. Teste de carga pontual num pórtico transversal com três variações e distribuição do peso em sete pontos.

\begin{tabular}{|c|c|c|}
\hline Carga de $184 \mathrm{kgf}$ & Carga de $284 \mathrm{kgf}$ & Carga de $348 \mathrm{kgf}$ \\
\hline Ponto A: $36 \mathrm{~kg}$ & Ponto A: 64 kg & Ponto A: $92 \mathrm{~kg}$ \\
\hline Ponto B: $28 \mathrm{~kg}$ & Ponto B: $28 \mathrm{~kg}$ & Ponto B: $28 \mathrm{~kg}$ \\
\hline Ponto C: $28 \mathrm{~kg}$ & Ponto C: $36 \mathrm{~kg}$ & Ponto C: $36 \mathrm{~kg}$ \\
\hline Ponto D: $0 \mathrm{~kg}$ & Ponto D: $28 \mathrm{~kg}$ & Ponto D: $36 \mathrm{~kg}$ \\
\hline Ponto E: $28 \mathrm{~kg}$ & Ponto E: $36 \mathrm{~kg}$ & Ponto E: $36 \mathrm{~kg}$ \\
\hline \multirow[t]{2}{*}{ Ponto F: 36 kg } & Ponto F: $64 \mathrm{~kg}$ & Ponto F: $92 \mathrm{~kg}$ \\
\hline & Ponto G: $28 \mathrm{~kg}$ & Ponto G: $28 \mathrm{~kg}$ \\
\hline Total & 284 & 348 \\
\hline
\end{tabular}

Os deslocamentos verticais devidos aos esforços de flexão e compressão (em centímetros) foram submetidos à análise de variância, e as médias dos tratamentos foram comparadas entre si, pelo teste de Tukey, a 5\% de probabilidade, por meio do software "StatGrafics Plus-4.1".

TABELA 2. Teste de carga pontual num pórtico longitudinal com três variações e distribuição do peso em seis pontos.

\begin{tabular}{cccc}
\hline & Carga de $184 \mathrm{kgf}$ & Carga de $384 \mathrm{~kg}$ & Carga de $496 \mathrm{~kg}$ \\
\hline & Ponto A: $36 \mathrm{~kg}$ & Ponto A: $64 \mathrm{~kg}$ & Ponto A: $84 \mathrm{~kg}$ \\
& Ponto B: $28 \mathrm{~kg}$ & Ponto B: $28 \mathrm{~kg}$ & Ponto B: $28 \mathrm{~kg}$ \\
& Ponto C: $28 \mathrm{~kg}$ & Ponto C: $100 \mathrm{~kg}$ & Ponto C: $136 \mathrm{~kg}$ \\
& Ponto D: $28 \mathrm{~kg}$ & Ponto D: $100 \mathrm{~kg}$ & Ponto D: $136 \mathrm{~kg}$ \\
& Ponto E: $36 \mathrm{~kg}$ & Ponto E: $64 \mathrm{~kg}$ & Ponto E: $84 \mathrm{~kg}$ \\
& Ponto F: $28 \mathrm{~kg}$ & Ponto F: $28 \mathrm{~kg}$ & Ponto F: $28 \mathrm{~kg}$ \\
\hline Total & 184 & 384 & 496 \\
\hline
\end{tabular}

Os deslocamentos verticais foram medidos com régua de aço em um ponto predeterminado, em um colmo de cada viga. Foram também observados os deslocamentos horizontais nas direções norte-sul e leste-oeste em três alturas das colunas $(4,0 ; 3,0$ e 2,0 m), porém esses dados serão objeto de estudos futuros.

\section{RESULTADOS E DISCUSSÃO}

Todos os deslocamentos verticais foram negativos, ou seja, para baixo, e o maior deslocamento após a aplicação das cargas foi observado no ponto 4 do pórtico transversal (Figura 7). Isso se deve ao fato de a viga de bambu sofrer esforço de compressão, gerando flexão em função de o vão livre $(6,0 \mathrm{~m})$ ser muito grande para o tipo de colmo de bambu utilizado. Portanto, a aplicação dessa viga como forma de resistência às cargas de compressão pode não ser ideal para a distância em questão, uma vez que os colmos utilizados não possuíram resistência suficiente para vencer o vão, devido à variação de diâmetro ao longo de seu comprimento.

Os deslocamentos verticais nos pontos 1 e 2 devem-se às forças exercidas nas amarrações das vigas junto às colunas (acomodação dos espaçadores e aos arames da amarração) e à flexão das colunas devido à compressão gerada pelas cargas. $\mathrm{O}$ comportamento desigual dos deslocamentos verticais referentes aos pontos 1 e 2 , observados na mesma figura, deve-se provavelmente às desigualdades de diâmetro e parede dos colmos de bambu, bem como à coincidência ou não de um 
nó sobre a amarração, o que pode favorecer maior resistência em função do maior diâmetro do colmo verificado no nó.

Observou-se maior variação do deslocamento vertical para a carga de $348 \mathrm{kgf}$ em relação ao ponto 1 , devido à quebra do espaçador de plástico, influenciando na média desse ponto. Um dos motivos para a quebra foi a presença de bolhas de ar no interior do espaçador de polietileno, geradas durante o processo de fabricação da peça.

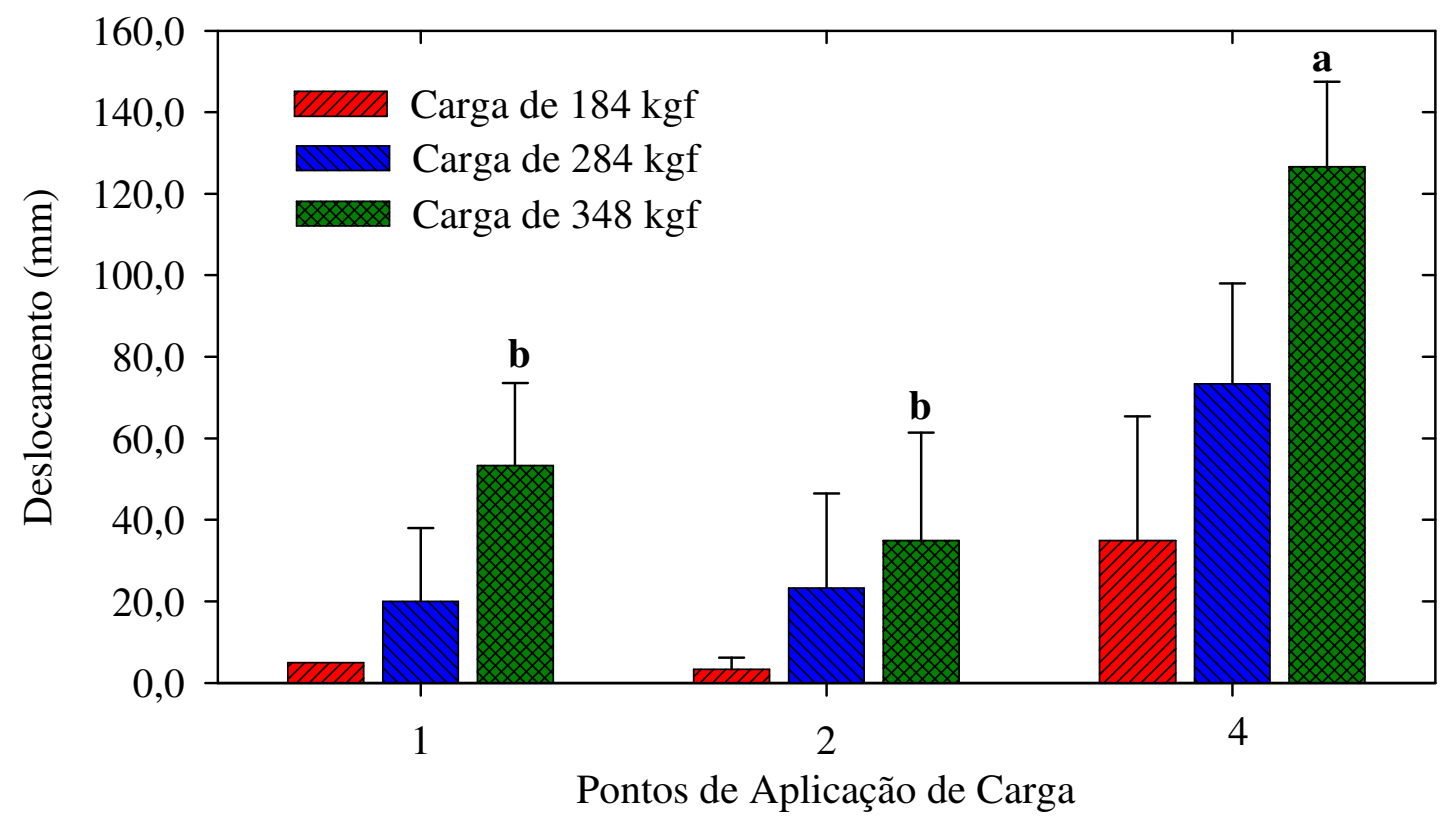

FIGURA 7. Variação média do deslocamento vertical da viga nos diferentes pontos de medição 1; 4 e 2, em função da carga aplicada no pórtico transversal. Médias seguidas da mesma letra não diferem significativamente entre si, pelo teste de Tukey, a 5\% de probabilidade.

\section{Avaliação do ensaio no pórtico longitudinal}

Para os ensaios de avaliação dos pórticos longitudinais, foi adotada a mesma metodologia utilizada nos transversais, com as cargas distribuídas em três espaçamentos (tratamentos) propostos entre colunas $(2,0 ; 2,5$ e $3,0 \mathrm{~m})$.

Observa-se, na Figura 8, que a variação média do deslocamento vertical nos pontos 5 e 6 (mediana do vão livre das vigas), para as distâncias de 2,0 e $2,5 \mathrm{~m}$, não diferiram significativamente entre si, porém houve diferença significativa para o espaçamento de $3,0 \mathrm{~m}$ em relação aos demais. Portanto, para menor custo de mão-de-obra e material, pode-se afirmar que o espaçamento de $2,5 \mathrm{~m}$ entre colunas, para o pórtico longitudinal, poderá ser utilizado sem o comprometimento da estrutura, desde que sejam adotados o mesmo desenho e a mesma metodologia construtiva. Cabe ressaltar que, ao se utilizarem vigas com comprimento de $6,0 \mathrm{~m}$ em uma das extremidades, o menor diâmetro dos colmos resultará em menor resistência; portanto, quanto menor o comprimento da viga, maior será sua resistência.

Observa-se, na Figura 9, que houve diferença significativa entre os deslocamentos ocorridos nos pontos 1 e 3 (colunas da extremidade) em relação ao ponto 2 (coluna central) para as cargas aplicadas no pórtico longitudinal. Ao se utilizar o espaçamento de 2,5 m, o deslocamento no ponto 2, em relação aos outros pontos das extremidades do pórtico, foi menor, o que já era esperado, pois os esforços são maiores nos pontos 1 e 3 devido ao tirantamento nas colunas da extremidade. Em função disso, torna-se conveniente utilizar colunas mais reforçadas nesses pontos, com seis colmos de bambu, por exemplo.

Nas Tabelas 3; 4 e 5, são apresentadas as "anovas" com as respectivas fontes de variação dos tratamentos. 


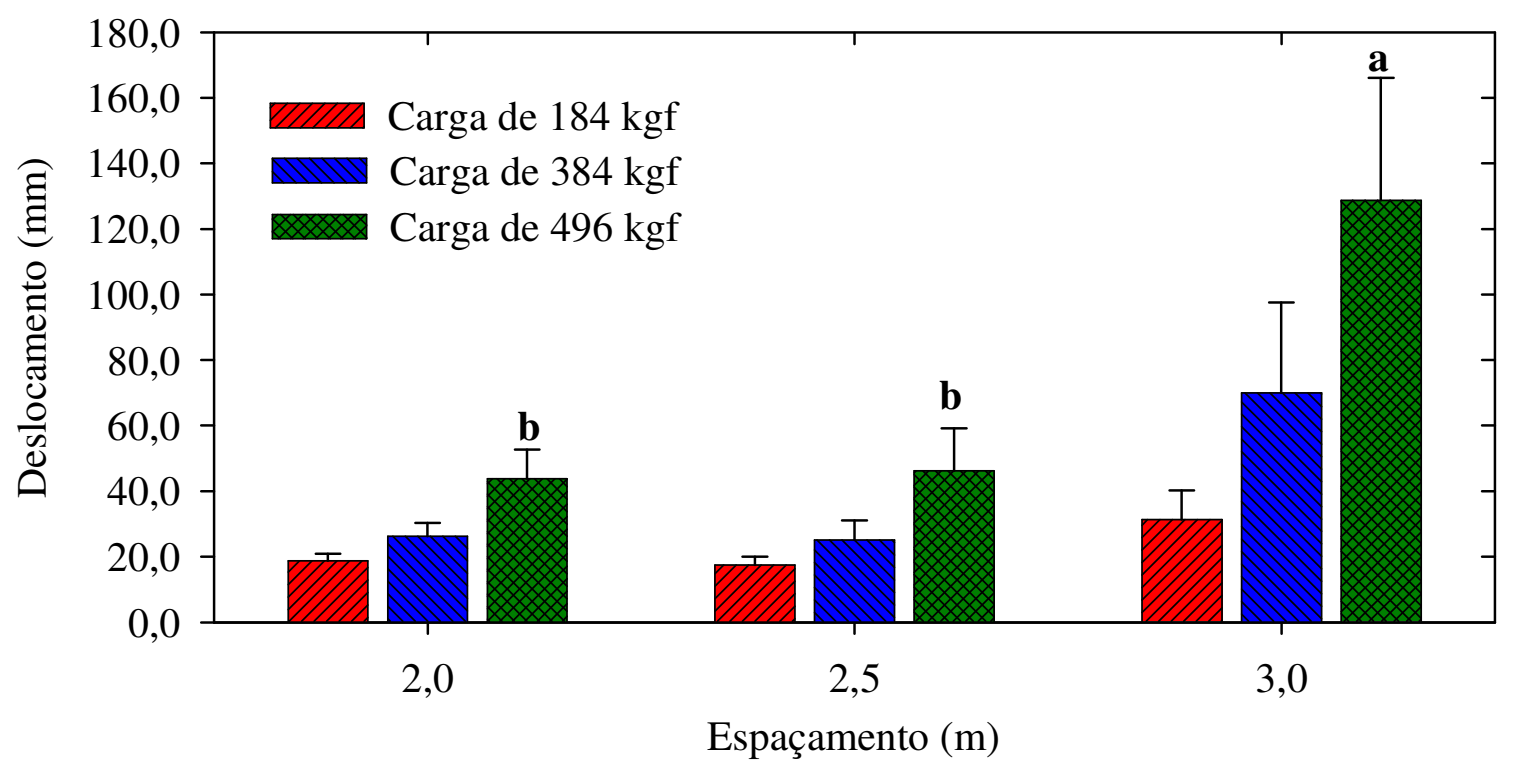

FIGURA 8. Variação média do deslocamento vertical das vigas nos pontos de medição 5 e 6 em função das cargas aplicadas no pórtico longitudinal. Médias seguidas da mesma letra não diferem significativamente entre si, pelo teste de Tukey, a $5 \%$ de probabilidade.

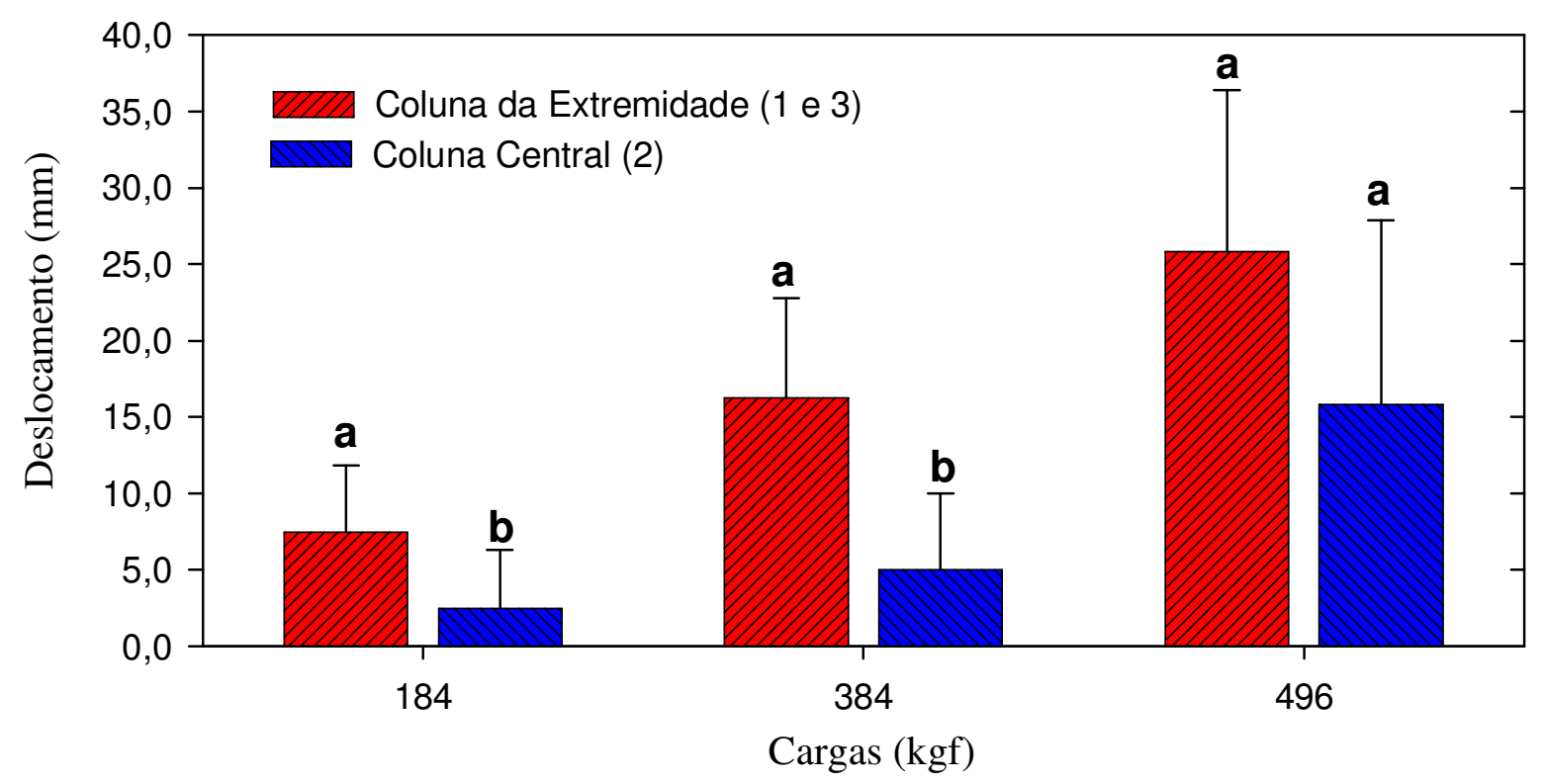

FIGURA 9. Variação dos deslocamentos verticais das colunas representadas pelos pontos 1, 2 e 3 em função das diferentes cargas aplicadas no pórtico longitudinal. Médias seguidas da mesma letra não diferem significativamente entre si, pelo teste de Tukey, a 5\% de probabilidade. As letras comparam médias entre colunas com a mesma carga.

TABELA 3. Anova dos dados apresentados na Figura 7, em relação à variação média da elevação da viga nos diferentes pontos de medição, em função da carga aplicada no pórtico transversal.

\begin{tabular}{|c|c|c|c|c|c|c|c|c|}
\hline Fontes de Variação & G.L. & $\begin{array}{l}\text { Soma dos } \\
\text { Quadrados }\end{array}$ & $\begin{array}{l}\text { Quadrado } \\
\text { Médio }\end{array}$ & $\begin{array}{l}\text { Valor de } \\
\text { "F" }\end{array}$ & Signif. & C.V.\% & $\begin{array}{l}\text { Desvio- } \\
\text { Padrão }\end{array}$ & $\begin{array}{l}\text { Erro- } \\
\text { Padrão }\end{array}$ \\
\hline $\begin{array}{l}\text { Variação entre } \\
\text { espaçamentos }\end{array}$ & 2 & $14.116,7$ & $7.058,33$ & 13,74 & 0,006 & & & \\
\hline Resíduo & 6 & $3.083,33$ & 513,89 & & & & & \\
\hline Total & 8 & 17.200 & & & & 31 & 46,36 & 15,45 \\
\hline
\end{tabular}


TABELA 4. Anova dos dados apresentados na Figura 8, em relação à variação média da elevação das vigas nos pontos de medição 4 e 5 , em função das cargas aplicadas no pórtico longitudinal.

\begin{tabular}{|c|c|c|c|c|c|c|c|c|}
\hline Fontes de Variação & G.L. & $\begin{array}{c}\text { Soma dos } \\
\text { Quadrados }\end{array}$ & $\begin{array}{l}\text { Quadrado } \\
\text { Médio }\end{array}$ & $\begin{array}{l}\text { Valor de } \\
\text { "F" }\end{array}$ & Signif. & C.V.\% & $\begin{array}{l}\text { Desvio- } \\
\text { Padrão }\end{array}$ & $\begin{array}{c}\text { Erro- } \\
\text { Padrão }\end{array}$ \\
\hline $\begin{array}{l}\text { Variação entre } \\
\text { espaçamentos }\end{array}$ & 2 & $18.716,7$ & 251,39 & 12,85 & 0,002 & & & \\
\hline Resíduo & 9 & $6.556,25$ & 26,1 & & & & & \\
\hline Total & 11 & $25.272,9$ & & & & 37 & 47,9 & 13,8 \\
\hline
\end{tabular}

TABELA 5. Anova da Figura 9 em relação à variação dos deslocamentos verticais das colunas representadas pelos pontos 1; 2 e 3, média em função das diferentes cargas aplicadas no pórtico longitudinal.

\begin{tabular}{|c|c|c|c|c|c|c|c|c|}
\hline Fontes de variação & G.L. & $\begin{array}{l}\text { Soma dos } \\
\text { Quadrados }\end{array}$ & $\begin{array}{c}\text { Quadrado } \\
\text { Médio }\end{array}$ & $\begin{array}{c}\text { Valor de } \\
\text { "F", }\end{array}$ & Signif. & C.V.\% & $\begin{array}{c}\text { Desvio- } \\
\text { Padrão }\end{array}$ & $\begin{array}{c}\text { Erro- } \\
\text { Padrão }\end{array}$ \\
\hline $\begin{array}{l}\text { Variação entre } \\
\text { espaçamentos }\end{array}$ & 2 & 502,78 & 251,39 & 9,63 & 0,002 & & & \\
\hline Resíduo & 15 & 391,67 & 26,11 & & & & & \\
\hline Total & 17 & 894,44 & & & & 48 & 7,2 & 1,7 \\
\hline
\end{tabular}

Os valores altos do coeficiente de variação observados nas tabelas de ANOVA foram devidos, provavelmente, à desuniformidade dos colmos de bambu em relação ao diâmetro, espessura de parede e distância entre nós.

Após a definição do melhor espaçamento entre colunas e do aprimoramento de alguns detalhes construtivos, foi construído o protótipo da casa de vegetação, conforme demonstrado na Figura 10. Nessa etapa, pode-se verificar o comportamento da estrutura em relação às forças exercidas pelo vento, sendo que a estrutura não resistiu a um vento lateral de $115 \mathrm{~km} \mathrm{~h}^{-1}$, tendo como principal fator o corte exercido pelo arame de amarração dos espaçadores, o que pode ser solucionado colocando-se uma sinta metálica (aço ou lata) para a proteção dos colmos nas amarrações.

Nova estrutura foi montada com diminuição da distância entre os espaçadores de $60 \mathrm{~cm}$ para $30 \mathrm{~cm}$, e a seleção de colmos de bambu com diâmetro médio maior do que $40 \mathrm{~cm}$ foi a forma de aumentar a resistência das colunas. Apesar de no período não ter havido ocorrência de ventos com velocidades superiores a $80 \mathrm{~km} \mathrm{~h}^{-1}$, a estrutura não sofreu nenhum dano.

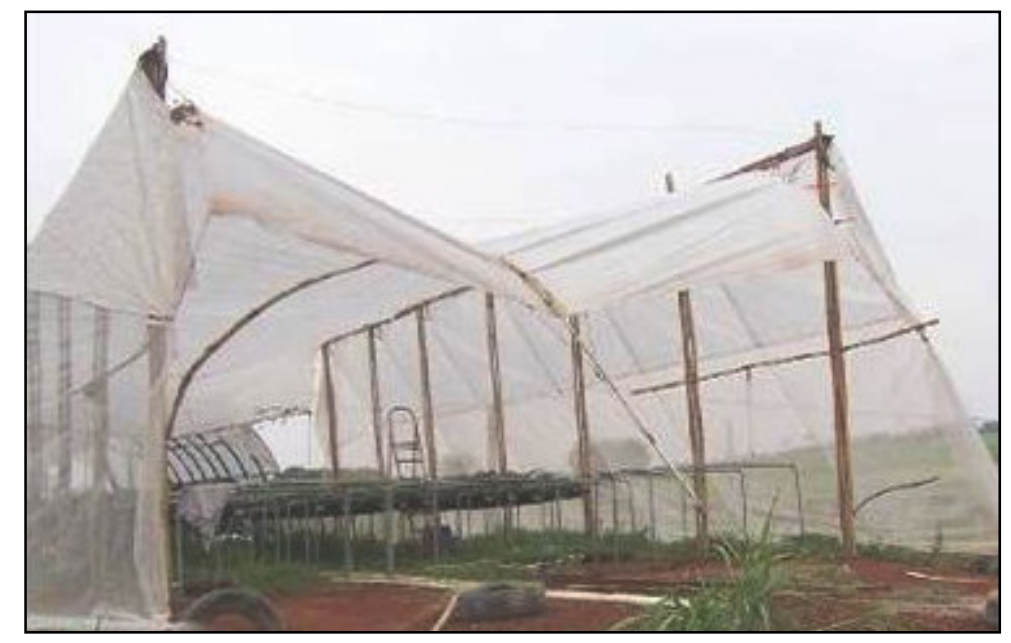

FIGURA 10. Vista da estrutura tipo tenda construída com bambu, após a fixação do plástico de cobertura. 


\section{CONCLUSÕES}

O espaçamento mais adequado entre as colunas do pórtico longitudinal para as condições do experimento foi o de $2,5 \mathrm{~m}$, economizando-se, assim, material e mão-de-obra.

O posicionamento da viga de bambu no pórtico transversal mostrou-se ineficiente para resistir aos esforços de compressão, em função do vão livre adotado e da espécie de bambu utilizada.

\section{REFERÊNCIAS}

BERALDO, A.L. Bambu Brasilis. Disponível em: <www.agr.unicamp.br/bambubrasilis >. Acesso em: 27 ago. 2002.

DELLA VECCHIA, P.T.; KOCH, P.S. História e perspectivas da produção de hortaliças em ambiente protegido no Brasil. Informe Agropecuário, Belo Horizonte, v.20, n.200/201, p.64-8, 1999.

FONTES, P.C.R. Produção de hortaliças em ambiente protegido: uma técnica a ser aprendida. Informe Agropecuário, Belo Horizonte, v.20, n. 200/201, p.1-2, 1999.

GHAVAMI, K. Bambu: um material alternativo na engenharia. Engenharia, São Paulo, n.492, p.23-7, 1992.

HIDALGO LÓPEZ, O. Bambú, su cultivo y aplicaciones en: Fabricación de papel, construcción, arquitectura, ingeniería e artesanía. Cali: Italgraf, 1974. 176 p.

RAJ, V. Treatise on utilization of bamboo as reinforcement in ferrocement. Journal of Ferrrocement, Bangkok, v.21, n.4, p.371- 81, oct. 1991. 